\title{
Biomarkers of Sarcopenia in Clinical Trials- Recommendations from the International Working Group on Sarcopenia
}

\section{Citation}

Cesari, Matteo, Roger A. Fielding, Marco Pahor, Bret Goodpaster, Marc Hellerstein, Gabor A. Van Kan, Stefan D. Anker, et al. 2012. Biomarkers of sarcopenia in clinical trials-recommendations from the International Working Group on Sarcopenia. Journal of Cachexia, Sarcopenia, and Muscle 3(3): 181-190.

\section{Published Version}

doi:10.1007/s13539-012-0078-2

\section{Permanent link}

http://nrs.harvard.edu/urn-3:HUL.InstRepos:10474255

\section{Terms of Use}

This article was downloaded from Harvard University's DASH repository, and is made available under the terms and conditions applicable to Other Posted Material, as set forth at http:// nrs.harvard.edu/urn-3:HUL.InstRepos:dash.current.terms-of-use\#LAA

\section{Share Your Story}

The Harvard community has made this article openly available.

Please share how this access benefits you. Submit a story.

Accessibility 


\title{
Biomarkers of sarcopenia in clinical trials-recommendations from the International Working Group on Sarcopenia
}

\author{
Matteo Cesari • Roger A. Fielding • Marco Pahor • Bret Goodpaster • Marc Hellerstein • \\ Gabor A. Van Kan • Stefan D. Anker • Seward Rutkove • J. Willem Vrijbloed • Maria Isaac • \\ Yves Rolland • Christine M'Rini • Mylène Aubertin-Leheudre • Jesse M. Cedarbaum • \\ Mauro Zamboni • Cornell C. Sieber • Didier Laurent • William J. Evans • Ronenn Roubenoff • \\ John E. Morley • Bruno Vellas • for the International Working Group on Sarcopenia
}

Received: 23 May 2012 / Accepted: 11 June 2012 / Published online: 3 August 2012

(C) The Author(s) 2012. This article is published with open access at Springerlink.com

\begin{abstract}
Sarcopenia, the age-related skeletal muscle decline, is associated with relevant clinical and socioeconomic negative outcomes in older persons. The study of this phenomenon and the development of preventive/therapeutic strategies represent public health priorities. The present document reports the results of a recent meeting of the International Working Group on Sarcopenia (a task force consisting of geriatricians and scientists from academia and industry) held on June 7-8, 2011 in Toulouse (France). The meeting was specifically focused at gaining knowledge on
\end{abstract}

This article is also appearing in Journal of Frailty \& Aging.

M. Cesari · G. A. Van Kan • Y. Rolland · B. Vellas

Gerontopôle and INSERM Unit 1027, Université de Toulouse,

Toulouse, France

R. A. Fielding $(\bowtie)$

Nutrition, Exercise Physiology, and Sarcopenia Laboratory, Jean

Mayer USDA Human Nutrition Research Center on Aging,

Tufts University,

711 Washington Street,

02111 Boston, MA, USA

e-mail: roger.fielding@tufts.edu

\section{Pahor}

Department of Aging and Geriatric Research, Institute on Aging,

University of Florida,

Gainesville, FL, USA

B. Goodpaster

Division of Endocrinology and Metabolism,

University of Pittsburgh,

Pittsburgh, PA, USA

M. Hellerstein

Department of Nutritional Sciences and Toxicology,

University of California at Berkeley,

San Francisco, CA, USA the currently available biomarkers (functional, biological, or imaging-related) that could be utilized in clinical trials of sarcopenia and considered the most reliable and promising to evaluate age-related modifications of skeletal muscle. Specific recommendations about the assessment of aging skeletal muscle in older people and the optimal methodological design of studies on sarcopenia were also discussed and finalized. Although the study of skeletal muscle decline is still in a very preliminary phase, the potential great benefits derived from a better understanding and treatment of this condition should

\section{S. D. Anker}

Department of Cardiology, Campus Virchow-Klinikum, Charité Universitätsmedizin Berlin,

Berlin, Germany

\section{S. D. Anker}

Centre for Clinical and Basic Research, IRCCS San Raffaele,

Rome, Italy

S. Rutkove

Harvard Medical School,

Boston, MA, USA

J. W. Vrijbloed

Neurotune AG,

Schlieren, Switzerland

M. Isaac

Human Medicine Special Areas, Scientific Advice Section,

European Medicines Agency,

London, UK

C. M'Rini

Institut Mérieux,

Lyon, France 
encourage research on sarcopenia. However, the reasonable uncertainties (derived from exploring a novel field and the exponential acceleration of scientific progress) require the adoption of a cautious and comprehensive approach to the subject.

\section{Introduction}

One of the most recognized changes in body composition with senescence is the loss of skeletal muscle mass. This loss occurs even among physically active older persons, and it was originally termed "sarcopenia" for the Greek words "flesh" and "loss" [1]. The age-related loss in skeletal muscle mass is associated with substantial social and economic costs and is characterized by impairments in strength, limitations in function, and ultimately physical disability and institutionalization [2-4]. In consideration of the increased

\author{
M. Aubertin-Leheudre \\ Départment de kinanthropologie, Université du Quebec, \\ Montreal, Canada \\ J. M. Cedarbaum \\ Clinical Research Operations, Neuroscience \& Neuromuscular \\ Disorders, Cytokinetics Inc., \\ South San Francisco, CA, USA
}

M. Zamboni

Department of Medicine, University of Verona,

Verona, Italy

C. C. Sieber

Institute for Biomedicine of Aging, Friedrich-Alexander-

University Erlangen-Nürnberg,

Nuremberg, Germany

D. Laurent

Novartis Institutes for Biomedical Research,

Basel, Switzerland

W. J. Evans

Muscle Metabolism DPU, Metabolic Pathways CEDD,

GlaxoSmithKline,

Research Triangle Park, NC, USA

R. Roubenoff

Musculoskeletal Translational Medicine, Novartis Institutes

for Biomedical Research,

Cambridge, MA, USA

J. E. Morley

University School of Medicine and GRECC,

VA Medical Center,

St. Louis, MO, USA

M. Cesari $(\bowtie)$

Institut du Vieillissement, Gerontopôle, Université de Toulouse,

37 Allées Jules Guesde,

31000 Toulouse, France

e-mail: macesari@gmail.com awareness of this syndrome and the continued rapid development of therapeutic strategies to slow or reverse sarcopenia, the International Working Group on Sarcopenia was convened to address issues related to the successful conduct of clinical trials in this area [5]. This task force, consisting of geriatricians and scientists from academia and industry, met again in Toulouse, France in June of 2011 to discuss the current state of the art in the development of biomarkers to be utilized in clinical trials on sarcopenia. The purpose of this meeting was to gain an understanding of the currently available parameters that could be utilized in clinical trials of sarcopenia and to discuss future research needs in this area. Specific topics that were addressed include: review of current consensus definitions of sarcopenia, the importance of muscle performance and quality, biomarkers in other clinical states and chronic diseases, potential biomarkers for sarcopenia, applications in clinical trials, and recommendations for future studies.

\section{Definition of sarcopenia}

Since the advent of the term "sarcopenia" in 1989, there has been a dramatic increase in publications in this area and clinical interest in this condition [6]. Originally described as the age-related decrease in skeletal muscle mass [7], until very recently, there has been a lack of consensus on the operational definition of sarcopenia without clinically appropriate correlates for this syndrome. In the past 2 years, a number of academic societies have put forward operational definitions of sarcopenia [8-11]. Although each consensus definition has some distinct features, there is general agreement among these groups on the definition of sarcopenia. A summary of consensus sarcopenia definitions is presented in Table 1. The characteristics of sarcopenia highlighted in these reports include an objective measure of muscle or fat free mass using dual energy X-ray absorptiometry (DXA) or computed tomography (CT), a reliable measure of muscle strength, and/or an objective test of physical functioning. Although the sequence of events and specific recommendations somewhat differ, the general approaches proposed require that patients be identified with measured deficits in physical function for which sarcopenia may be the cause and subsequently quantification of muscle strength and mass to definitively confirm the diagnosis.

\section{Definition of a biomarker}

A biomarker is defined as "a characteristic that is objectively measured and evaluated as an indicator of normal biological processes, pathogenic processes, or pharmacologic responses to a therapeutic intervention" [12]. Hence, biomarkers support the diagnosis, facilitate the tracking of changes 
over time, and help clinical and therapeutic decisionmaking processes. Taking this definition into account, the functional, biological, or imaging-related parameters considered in the present document will be hereby generally referred to with the term "biomarker."

There are currently numerous parameters that are potentially able to track the age-related skeletal muscle decline. Depending on the parameter chosen to define sarcopenia, different information might be obtained. Such variability depends on the specific characteristics of each parameter and the mechanisms measured by the parameter. The intrinsic (e.g., accuracy, specificity, sensitivity) and extrinsic (e.g., cost, availability, time to be performed) properties of each biomarker will largely drive its use in research trials, making it more suitable for screening, baseline evaluation, and/or definition of outcomes (Table 2).

The use of biomarkers in a given study must be "fit for purpose." Thus, several different biomarkers may be required to support different aspects of the development of a therapeutic intervention. For example, biomarkers for detection and diagnosis may not be the same as those that ideally track disease progression. Likewise, for new therapeutic agents, a single assay may not suffice as a biomarker reflecting both target engagement and the pharmacodynamic effects of a drug.

\section{Muscle quantity versus muscle quality}

Although muscle mass can objectively define the presence of sarcopenia, several components of skeletal muscle function are not adequately captured by simply measuring mass or cross-sectional area. It is now clear that there is a certain degree of divergence between changes in muscle mass and alterations in muscle performance. The well-described decline in skeletal muscle mass in older adults is a critical determinant of age-related weakness, which is defined as a reduction in maximal voluntary joint torque or power. Yet, it is now clear that the relationship between force production capability and muscle size in older adults is less robust than it is in young people [13]. Indeed, longitudinal studies have demonstrated that the age-related decline in muscle strength far exceeds the observed changes in muscle mass or size, particularly in weight-stable individuals $[14,15]$. Furthermore, longitudinal studies indicate that maintenance or even gain of muscle mass may not prevent weakness in older adults $[15,16]$. In addition, a number of age-related changes in force production capability are not readily explained by a reduction in muscle mass, including decreased specific force (force per cross sectional area) [17, 18] and slower rate of isometric force production (expressed relative to peak torque or to body weight) $[19,20]$. Furthermore, voluntary weight loss leads to reductions in muscle mass/size with no declines 
Table 2 Possible biomarkers to be used in trials on sarcopenia

\begin{tabular}{llll}
\hline $\begin{array}{l}\text { Inclusion- } \\
\text { exclusion } \\
\text { criteria }\end{array}$ & $\begin{array}{l}\text { Baseline } \\
\text { evaluation }\end{array}$ & $\begin{array}{l}\text { End-point } \\
\text { assessment }\end{array}$ \\
\hline
\end{tabular}

\begin{tabular}{|c|c|c|c|}
\hline \multicolumn{4}{|l|}{ Muscle function } \\
\hline $\begin{array}{l}\text { Physical performance } \\
\text { measures }\end{array}$ & +++ & +++ & +++ \\
\hline Muscle strength measures & +++ & +++ & +++ \\
\hline Disability & +++ & +++ & +++ \\
\hline \multicolumn{4}{|l|}{ Muscle mass } \\
\hline Anthropometry & + & - & - \\
\hline $\begin{array}{l}\text { Bioelectrical impedance } \\
\text { analysis }\end{array}$ & + & + & + \\
\hline $\begin{array}{l}\text { Dual energy X-ray absorp- } \\
\text { tiometry }\end{array}$ & +++ & ++ & ++ \\
\hline Computerized tomography & ++ & +++ & +++ \\
\hline $\begin{array}{l}\text { Magnetic resonance } \\
\text { imaging }\end{array}$ & ++ & +++ & +++ \\
\hline Echography & ++ & ++ & ++ \\
\hline $\begin{array}{l}\text { Electrical impedance } \\
\text { myography }\end{array}$ & + & ++ & ++ \\
\hline \multicolumn{4}{|c|}{ Mechanisms, biological confounders ${ }^{a}$} \\
\hline Inflammation & ++ & ++ & ++ \\
\hline Oxidative damage & ++ & ++ & ++ \\
\hline Antioxidants & ++ & ++ & ++ \\
\hline Apoptosis & + & ++ & ++ \\
\hline $\begin{array}{l}\text { Nutritional parameters } \\
\text { (albumin, hemoglobin, } \\
\text { urinary creatinine, etc.) }\end{array}$ & +++ & ++ & ++ \\
\hline $\begin{array}{l}\text { Hormones } \\
\text { (dehydroepiandrosterone, } \\
\text { testosterone, insulin-like } \\
\text { growth factor-1, etc.) }\end{array}$ & ++ & ++ & ++ \\
\hline
\end{tabular}

- not recommended for this use; + may be of use, but severely limited; ++ suitable for this use; +++ recommended for this use

${ }^{\text {a }}$ The importance of all of these biomarkers in the evaluation of sarcopenia will largely depend on the study hypotheses, the specific aims, and/or the target population

in muscle strength [21]. It is also noteworthy that pharmacologic interventions that increase muscle mass/size do not necessarily improve voluntary strength. Similarly, physical activity interventions that increase muscle strength do not necessarily augment muscle size $[22,23]$. Noticeably, gains in muscle strength secondary to increased physical activity generally precede measurable changes in skeletal muscle mass/size.

The progressive muscle atrophy with aging is associated with a loss of overall muscle force and changes in force and power generation of the remaining muscle fibers [24]. However, several additional physiological mechanisms that accompany the phenomenon of sarcopenia may directly influence muscle function and force production with advancing age. Recent evidence has shown that adipose tissue accumulation around and between muscle fibers concomitant with reductions in muscle cross-sectional area occurs with aging, and that this skeletal muscle attenuation is inversely associated with muscle performance [18, 25]. Age-related changes in the nervous system may also play a substantial role in the decline in muscle power generation [26]. These include loss of motor neurons and concomitant remodeling of motor units through collateral reinnervation [27], impairment of neuromuscular activation observed as decreased maximal motor unit firing rates [28-30], and uncoordinated patterns of intermuscular neural activation [31]. Finally, changes in individual muscle fiber composition and intrinsic contractile properties may influence the decline in muscle force among older adults. For instance, cross-sectional observations suggest that reductions in muscle torque may be related to changes in fiber composition and, in particular, to the preferential atrophy of type II (fast-twitch) fibers with aging [32]. Specific changes in the intrinsic ability of aged muscle to generate force have also been observed [33]. Decreases in specific force (force normalized per cross sectional area) and unloaded shortening velocity in type I and IIA fibers have been reported in older males compared with young controls [32, 34]. Conversely, recent longitudinal data have demonstrated that, despite reductions in whole muscle crosssectional area, single muscle fiber contractile function is preserved with advancing age as existing fibers may compensate and partially correct these deficits, therefore maintaining optimal force-generating capacity [14].

Although precise and valid measures of muscle mass are important components of sarcopenia assessment, these gross measures of muscle size do not adequately account for the dynamic components (force, power, activation) of muscle function that are responsible for performing activities of daily living. Future trials on sarcopenia adopting clinically meaningful endpoints should evaluate these key biomarkers of muscle function through the use of state-of-the-art methodologies.

\section{Quantitative assessment of sarcopenia}

The bidimensional definition of sarcopenia simultaneously includes a functional parameter (i.e., muscle performance) and a quantitative index (i.e., muscle mass). Therefore, techniques aimed at capturing the objective amount of skeletal muscle mass are required. Multiple methodologies are currently available to accomplish this task [35].

DXA is the most commonly used imaging technique for several reasons: first of all, because it is commonly available in clinical and research settings, being relatively inexpensive, sufficiently precise, and well-accepted by older persons. Second, the initial operative definition of sarcopenia proposed by Baumgartner and colleagues [3] was based on appendicular lean mass measured by DXA. Later on, DXA was used to provide alternative definitions of sarcopenia based on the fat-adjusted residual method 
[36]. Nevertheless, it cannot be ignored that the first operative definition is dated more than 10 years, and during this time, several steps forward have been made in refining imaging techniques as well as understanding the sarcopenia phenomenon.

The identification of the "gold standard" for the quantitative evaluation of muscle mass in clinical trials (which is currently lacking) should be based on criteria of accuracy (i.e., the degree of conformity of a measure to a standard or a true value), precision (i.e., the degree of refinement with which an operation is performed or a measurement stated), reproducibility (i.e., the quality of being reproducible under the same operating conditions over a period of time or by different operators), sensitivity to change (i.e., the degree of being modified by interventions), and accessibility (i.e., its usual availability in research and clinical centers).

DXA currently represents the more accessible technique for body composition assessment. It may accurately provide estimates of lean, fat, and bone tissues in the entire body or in specific regions. Moreover, it is inexpensive and quick to be performed. The radiation exposure associated with DXA is low and highly acceptable (about 1 mrem, a quantity similar to that of a 3-day background). The main limitations of this imaging approach reside in some analytical differences across manufacturers and models, and the risk of biased results due to the low differentiation between water and bone-free lean tissue.

$\mathrm{CT}$ accurately measures a direct physical property of the muscle (e.g., cross-sectional area and volume). It also allows the evaluation of muscle density (a parameter related to intramyocellular lipid deposits) as well as subcutaneous and intramuscular adipose tissue deposition. The radiation exposure associated with this technique is higher (i.e., about 15 mrem) than with DXA.

Magnetic resonance imaging (MRI) presents a high agreement with $\mathrm{CT}$ and provides similar measures. It does not involve radiation exposure and also has the additional capacity of multiple slice acquisition, thus rendering $3 \mathrm{D}$ volumetric estimates. The lack of radiation exposure makes MRI the method of choice for many studies where ethics committee or national authority approval is more difficult to obtain for $\mathrm{CT}$. The major limitations of this methodology reside in the higher technical complexity and costs, and in the inapplicability to subjects with older models of implanted metal devices (e.g., joint prostheses, pace-makers, etc.). Both CT and MRI may be limited in the ability to accommodate very obese individuals.

Finally, it needs to be emphasized that imaging provides information only about one of the two sarcopenia dimensions. As discussed earlier, changes in muscle function and quantity do not necessarily follow similar trajectories with aging [37]. Therefore, interventions able to increase lean mass may not necessarily produce parallel gains in strength and vice versa [38]. To overcome this issue and include the two components of sarcopenia in the same variable, it has been proposed to compute an index of skeletal muscle quality derived from the ratio between strength and mass $[15,39,40]$.

One of the most recently developed techniques which might find larger application in the near future for the evaluation of sarcopenia is the electrical impedance myography (EIM) [41]. This is a noninvasive, painless approach based on the surface application and measurement of a high-frequency, lowintensity electrical current applied to specific muscles. EIM detects changes in the conductivity and permittivity of skeletal muscle caused by alterations in muscle composition and structure. EIM is repeatable and sensitive to skeletal muscle changes in patients with amyotrophic lateral sclerosis [42]. Moreover, its changes over time may also have clinical relevance as they are predictive of survival in animal models of amyotrophic lateral sclerosis [43]. Finally, it is also noteworthy that the EIM phase shows a consistent inverse relationship with age [44].

An alternative method to measure skeletal muscle size is by ultrasonography. This technique has shown to be a valid (versus MRI-based measurements) and highly reliable way for assessing cross-sectional areas of large individual human muscles [45]. It is particularly useful in mobility-impaired subjects who cannot easily be transported to scanners such as $\mathrm{CT}$ or MRI machines.

Also remarkable is the development of mass isotopomer distribution analysis based on the evaluation of protein and proteome synthesis rate obtained by heavy water labeling $[46,47]$. Although this technique can still be considered suitable mainly for research settings, its flexibility and the large amount of information it provides about a wide spectrum of proteins make it extremely promising.

Other techniques are also available to detect sarcopenia, but their limited validation, low accuracy, and difficult largescale implementation discourage their use. For example, bioelectrical impedance analysis (BIA) is a popular, very simple, and low-cost technique, but its results are far from being accurate. The BIA technique is based on the notion that tissues rich in water and electrolytes are less resistant to the electrical passage than adipose tissue. The BIA is therefore based on a single body resistance parameter (not a direct measure of skeletal muscle), and its results can be easily altered by fluid retention and health status in general. For these reasons, a recent consensus paper by the Society of Sarcopenia, Cachexia and Wasting Disorders has discouraged the use of BIA for the assessment of sarcopenia [9].

\section{Definition of critical thresholds}

There is still resistance to accept sarcopenia as a clinical condition despite its well-established relationship with major health-related negative events (in particular, mobility and physical disability) [8]. This issue might (at least partly) be 
explained by the current lack of clinically relevant thresholds that distinguish normal from abnormal values of skeletal muscle mass.

Several approaches can be adopted to identify critical cut-points. A paradigmatic example potentially lending support to the operative definition of sarcopenia might be provided by the approach previously adopted to identify osteoporosis on the basis of bone mineral density. In fact, approaches that have been developed for bone and osteoporosis may serve well for skeletal muscle and sarcopenia. The clinical definition of a specific condition (which will consequently lead to the indication for treatment) might be based on:

1. A parallel clinical diagnosis. For osteoporosis, diagnosis can be obtained by evaluating the presence of vertebral fractures or deformities at the X-ray examination. Vertebral fractures indicate decreased bone strength, regardless of bone mineral density. It is well established that patients with vertebral fractures present an increased risk of new events and therefore require treatment. This approach is legitimate and may well work, but may find some limitations when applied in primary prevention.

2. A biological assessment. Given its well-established association with fracture risk, bone mineral density may represent the key parameter on which to rely to determine the presence or absence of osteoporosis. However, bone mineral density (like any other biological marker) exists as a continuous variable, does not present a clear threshold, and is parallel to gradients of risk. Although necessary to provide clinical relevance to biological markers, any categorization will lead to a loss of information and will inevitably introduce an "arbitrary" decision. For the definition of osteoporosis, the cut-off defining the disease was arbitrarily set by a committee which judged the -2.5 standard deviations at the T-score as an adequate match between risk and prevalence. One major problem with the bone definition that should not be repeated for sarcopenia is the inclusion of osteopenia. Osteopenia (defined by a bone mineral density Tscore ranging between -1 and 2.5) encompasses about $50 \%$ of the female healthy population and has led to confusion and concerns among policy-makers regarding the validity of a construct that cannot really be considered abnormal. An approach consistent with this model has also been adopted in the definition of other clinical conditions such as anemia [48].

3. The risk of adverse clinical outcomes. The indication to treatment of a specific condition (e.g., osteoporosis) might be based on the evaluation of risk of events (i.e., fractures) resulting from the assessment of multiple factors (which may even not include bone mineral density) [49]. This approach will not be exclusively based on the single evaluation of a (potentially inaccurate and/ or arguable) biomarker, but on a more comprehensive screening and on cost-effectiveness analyses (e.g., treat if the 10-year risk is exceeding a critical threshold). With this rationale, the FRAX [50] and QFractureScores [51] algorithms were recently developed to guide osteoporosis treatment.

In summary, the presence of sarcopenia might be determined by (1) relying on a clinical diagnosis closely related to skeletal muscle decline (e.g., mobility disability) after exclusion of secondary causes, (2) a representative scientific committee identifying a critical threshold for a biological parameter directly representative of skeletal muscle health, and/or (3) developing a risk index to guide treatment.

\section{Biological markers of sarcopenia}

Given the syndromic nature of sarcopenia, intervention strategies aimed at preventing/treating its process might need to target multiple risk factors. In this context, several biological markers have been shown to be associated with skeletal muscle mass, strength, and function, thus representing potential markers for the effect of the studied interventions. Such a list is quite long, and each biomarker identifies a specific mechanism contributing the age-related skeletal muscle decline, although they are not specific to muscle and many are likely to turn out to be only weakly associated with clinically relevant outcomes. The most common markers are inflammatory biomarkers [e.g., C-reactive protein $[52,53]$, interleukin-6 [52-54], and tumor necrosis factor- $\alpha[52,54]]$, clinical parameters [e.g., hemoglobin $[55,56]$, serum albumin $[57,58]$, and urinary creatinine [59]], hormones [e.g., dehydroepiandrosterone sulfate [60], testosterone [61], insulin-like growth factor-1 [62], and vitamin D [63-65]], products of oxidative damage [e.g., advanced glycation end-products [66], protein carbonyls [67, 68], and oxidized low-density lipoproteins [69]], or antioxidants [e.g., carotenoids [70, 71] and $\alpha$-tocopherol [70]].

Other promising biomarkers have been identified in the last years and may represent useful parameters to more directly explore sarcopenia because they are closely related to skeletal muscle changes. For example, plasma concentrations of procollagen type III N-terminal peptide (P3NP) represent an interesting marker of skeletal muscle remodeling $[72,73]$. P3NP is a fragment released by the cleavage of procollagen type III to generate collagen III (a protein produced in soft connective tissues, skin, and muscle). Preliminary studies have also suggested an interesting role played by biomarkers specifically linked to the neuromuscular junction in evaluating skeletal muscle modifications [74, 75]. 


\section{Clinical outcome measures of sarcopenia}

Ultimately, the goal of clinical trials for sarcopenia treatments will require the evaluation of clinical benefit. In fact, clinical measures can also be considered as biomarkers as they reflect the impact of the pathological process of sarcopenia on the patient's health. The assessment of measures of muscle strength (e.g., hand grip), muscle power (e.g., leg extension power), and physical performance [e.g., Short Physical Performance Battery [4] and gait speed tests] comprise important indices of the individual's physical function. In addition, functional outcome measures will need to be developed in order to help understand the impact of any treatment-related quantitative gains in performance on the person's daily life.

\section{Recommendations}

\subsection{Adoption of comprehensive operative definitions}

The lack of a unique operative definition of sarcopenia and the numerous methodological issues could potentially hinder efforts to study sarcopenia and to develop effective treatments. Such difficulties should not hamper the process of exploring this syndrome which severely affects the health status of millions of older persons. The current ambiguities can be easily overcome by adopting flexible and comprehensive approaches in the design of studies, for example, by avoiding reliance on a single parameter or technique to evaluate age-related skeletal muscle decline. The adoption of a variety of assessment approaches in combination is agreeable. Although this might lead to the risk of conflicting results (and increase the need of resources), it will serve to (1) capture different domains of the sarcopenia syndrome, (2) provide useful insights about the pathophysiological process underlying this phenomenon, and (3) facilitate the development and use of the findings in future and more definitive studies. In this context, it is noteworthy the lack of studies simultaneously testing different techniques measuring skeletal muscle (e.g., MRI, CT, DXA, etc.) in relationship with clinically meaningful outcomes. Such studies might greatly help in the standardization of instruments and in the adoption of an univocal direction in the study of sarcopenia.

9.2 MRI and CT scan to be equally considered as "gold standard" imaging techniques

It is now clear that, to be adequately assessed, the sarcopenia phenomenon cannot merely rely on the evaluation of the contractile part of skeletal muscle. The close relationship between lean mass and adipose tissue in determining age- related decline of skeletal muscle is evident [38, 76, 77]. Therefore, techniques allowing the simultaneous evaluation of fat and muscle should be preferred. DXA, CT, and MRI are the most important assessment instruments. CT and MRI should be considered the "gold standard" techniques. The balance of pros and cons for both CT and MRI does not allow a clear indication on which of the two should be preferred. Resources, instrument availability, and need of details will represent the factors guiding the investigator's preference for one over the other. On the other hand, DXA should not be discarded and still represents the instrument more likely to promote the "clinical relevance" of sarcopenia. For its characteristics, DXA may be an extremely interesting methodology to be used for preliminary screening. Moreover, its use in combination with either CT or MRI will help drive the research in the field towards more clinical aspects. While imaging and other biomarkers will be valuable tools for initial proof of concept studies, assessment tools for evaluating the effect of treatments on outcomes reflecting clinical benefit will be required to support eventual pivotal studies.

\subsection{Adequate length of study}

To evaluate the efficacy of a specific intervention on sarcopenia, it is necessary that the follow-up will be sufficiently long to allow the hypothesized modifications of biomarkers. Surely, not all biomarkers will be similarly influenced by the intervention. Such variations will depend on multiple factors, including the population characteristics, the type and strength of the tested intervention, and the sensibility of the biomarker to changes. However, 6 months have been generally indicated as the minimum timeframe to expect changes in imaging parameters.

\subsection{Sarcopenia is a "work in progress"}

The study of sarcopenia is still in its infancy, but we have clearly acknowledged the great potential benefits arising from the understanding and treatment of this condition at both person and population levels. Taking together the uncertainties of exploring a novel field with the exponential acceleration of scientific progress, it is currently difficult to provide long-lasting statements, recommendations, and guidelines. It is likely that what seems reasonable today will be confounded by several studies in the near future. For this reason, extreme caution is needed to avoid jeopardizing the future development of research in the field. It is important to consider the study of sarcopenia as a "work in progress," always amenable to changes and redirections. After all, the first phase II trials in this syndrome are just starting, and this is the appropriate time to raise doubts and pose questions. With time, a stronger foundation for sarcopenia 
research will be developed, which will ultimately lead to larger scale and more definitive studies. In this context, it is critical that an ongoing dialogue be initiated and sustained among investigators with an interest in age-dependent decline of muscle.

Acknowledgements Dr. Fielding's contribution is based upon the work supported by the US Department of Agriculture, under agreement No. 58-1950-7-707. The authors of this manuscript certify that they comply with the ethical guidelines for authorship and publishing in the Journal of Cachexia, Sarcopenia and Muscle [78].

Members of the International Working Group on Sarcopenia: Gabor Abellan Van Kan, France; Sandrine Andrieu, France; Stefan D. Anker, Germany; Patricia Anthony, Switzerland; Christian Asbrand, Germany; Mylène Aubertin-Leheudre, Canada; Sebastien BarbartArtigas, Canada; Olivier Benichou, France; Cécile Bonhomme, France; Pascale Borensztein, France; Denis Breuillé, Switzerland; Sergio Castro Henriquez, Chile; Jesse M. Cedarbaum, USA; Matteo Cesari, France; Patricia Chatelain, France; Wm. Cameron Chumlea, USA; Richard V. Clark, USA; Capucine De Meynard, France; William J. Evans, USA; Gary Fanjiang, USA; Luigi Ferrucci, USA; Roger A. Fielding, USA; Philippe Garnier, France; Sophie Gillette-Guyonnet, France; Bret Goodpaster, USA; Marie-Françoise Gros, France; Luis Miguel F. Gutierrez Robledo, Mexico; Marc Hellerstein, USA; Kelly Krohn, USA; Maria Isaac, United Kingdom; Didier Laurent, Switzerland; Menghua Luo, USA; Hélène Matheix-Fortunet, France; Inge Mohede, The Netherlands; John E. Morley, USA; Christine M'Rini, France; Ramon Navarro, France; Bruno Oesch, Switzerland; Reinhard Ommerborn, Germany; Marco Pahor, USA; Patrick Ritz, France; Yves Rolland, France; Daniel Rooks, USA; Ronnen Roubenoff, USA; Fariba Roughead, Switzerland; Seward Rutkove, USA; Cornel C. Sieber, Germany; Michèle Storrs-Malibat, France; Stephanie Studenski, USA; Yannis Tsouderos, France; Bruno Vellas, France; Sjors Verlaan, The Netherlands; Stephan Von Haehling, Germany; J. Willem Vrijbloed, Switzerland; Sander Wijers, The Netherlands; Mauro Zamboni, Italy.

Conflicts of interest $\mathrm{MC}$ has received consultancy fees from SanofiAventis and Pfizer; RAF is a consultant with Merck, Eli Lilly, Cytokinetics, DMI, Kraft Foods, and Unilever; MH is a stockholder, chairmen of scientific advisory board, and consultant for KineMed, Inc.; SA is a consultant with Brahms, Vifor, Professional Dietetics, PsiOxus, and Takeda; receives research support from Vifor and BG Medicine; and has received fees for speaking at meetings from Brahms and Vifor; SR has equity in and receives consulting income from Convergence Medical Devices, Inc; WV is an employee and a shareholder of Neurotune AG; YR receives support from Lactalis, Lundbeck, Lilly, Nutricia, Servier, Cheisi, Ipsen, and Novartis; JMC is an employee and a shareholder of Cytokinetics, Inc; MZ has received a fee from Abbot for a conference; DL and RR are employed by Novartis; WJE is employed by GlaxoSmithKline; JEM is a consultant and a stokeholder of Mattern Pharmaceuticals and a consultant for Sanofi-Aventis; BV is a consultant and a member of the Advisory Board with Novartis, Servier, and Nestlè. MP, BG, GAVK, MI, CMR, MAL, and CCS have no conflict of interest to declare.

Disclaimer Any opinions, findings, conclusions, or recommendations expressed in this publication are those of the authors and do not necessarily reflect the position of the supporting organizations or agencies.
Open Access This article is distributed under the terms of the Creative Commons Attribution Noncommercial License which permits any noncommercial use, distribution, and reproduction in any medium, provided the original author(s) and the source are credited.

\section{References}

1. Rosenberg IH. Sarcopenia: origins and clinical relevance. J Nutr. 1997;127:990S-1S.

2. Frontera WR, Hughes VA, Lutz KJ, Evans WJ. A cross-sectional study of muscle strength and mass in 45- to 78-yr-old men and women. J Appl Physiol. 1991;71:644-50.

3. Baumgartner RN, Koehler KM, Gallagher D, Romero L, Heymsfield SB, Ross RR, et al. Epidemiology of sarcopenia among the elderly in New Mexico. Am J Epidemiol. 1998;147:755-63.

4. Guralnik JM, Ferrucci L, Simonsick EM, Salive ME, Wallace RB. Lower-extremity function in persons over the age of 70 years as a predictor of subsequent disability. N Engl J Med. 1995;332:556-61.

5. Chumlea WC, Cesari M, Evans WJ, Ferrucci L, Fielding RA, Pahor M, et al. Sarcopenia: designing phase IIB trials. J Nutr Health Aging. 2011;15:450-5.

6. Pahor M, Cesari M. Designing phase II B trials in sarcopenia: the best target population. J Nutr Health Aging. 2011;15:725-30.

7. Evans WJ. What is sarcopenia? J Gerontol A Biol Sci Med Sci. 1995;50 Spec No:5-8.

8. Fielding RA, Vellas B, Evans WJ, Bhasin S, Morley JE, Newman $\mathrm{AB}$, et al. Sarcopenia: an undiagnosed condition in older adults. Current consensus definition: prevalence, etiology, and consequences. International Working Group on Sarcopenia. J Am Med Dir Assoc. 2011;12:249-56.

9. Morley JE, Abbatecola AM, Argiles JM, Baracos V, Bauer J, Bhasin S, et al. Sarcopenia with limited mobility: an international consensus. J Am Med Dir Assoc. 2011;12:403-9.

10. Cruz-Jentoft AJ, Baeyens JP, Bauer JM, Boirie Y, Cederholm T, Landi F, et al. Sarcopenia: European consensus on definition and diagnosis: Report of the European Working Group on Sarcopenia in Older People. Age Ageing. 2010;39:412-23.

11. Muscaritoli M, Anker S, Argilés J, Aversa Z, Bauer J, Biolo G et al. Consensus definition of sarcopenia, cachexia and pre-cachexia: joint document elaborated by Special Interest Groups (SIG) “cachexia-anorexia in chronic wasting diseases" and "nutrition in geriatrics". Clinical nutrition (Edinburgh, Scotland). 2010;

12. Group BDW. Biomarkers and surrogate endpoints: preferred definitions and conceptual framework. Clin Pharmacol Ther. 2001;69:89-95.

13. Clark BC, Manini TM. Sarcopenia $=/=$ dynapenia. J Gerontol A Biol Sci Med Sci. 2008;63:829-34.

14. Frontera WR, Reid KF, Phillips EM, Krivickas LS, Hughes VA, Roubenoff R, et al. Muscle fiber size and function in elderly humans: a longitudinal study. J Appl Physiol. 2008;105:637-42.

15. Goodpaster BH, Park SW, Harris TB, Kritchevsky SB, Nevitt M, Schwartz AV, et al. The loss of skeletal muscle strength, mass, and quality in older adults: the health, aging and body composition study. J Gerontol A Biol Sci Med Sci. 2006;61:1059-64.

16. Hughes VA, Frontera WR, Wood M, Evans WJ, Dallal GE, Roubenoff $\mathrm{R}$, et al. Longitudinal muscle strength changes in older adults: influence of muscle mass, physical activity, and health. J Gerontol A Biol Sci Med Sci. 2001;56:B209-17.

17. Morse CI, Thom JM, Davis MG, Fox KR, Birch KM, Narici MV. Reduced plantarflexor specific torque in the elderly is associated with a lower activation capacity. Eur J Appl Physiol. 2004;92:219-26. 
18. Goodpaster BH, Carlson CL, Visser M, Kelley DE, Scherzinger A, Harris TB, et al. Attenuation of skeletal muscle and strength in the elderly: the Health ABC Study. J Appl Physiol. 2001;90: 2157-65.

19. Klass M, Baudry S, Duchateau J. Age-related decline in rate of torque development is accompanied by lower maximal motor unit discharge frequency during fast contractions. J Appl Physiol. 2008;104:739-46.

20. Laroche DP, Knight CA, Dickie JL, Lussier M, Roy SJ. Explosive force and fractionated reaction time in elderly low- and high-active women. Med Sci Sports Exerc. 2007;39:1659-65.

21. Wang X, Miller GD, Messier SP, Nicklas BJ. Knee strength maintained despite loss of lean body mass during weight loss in older obese adults with knee osteoarthritis. J Gerontol A Biol Sci Med Sci. 2007;62:866-71.

22. Fiatarone MA, O'Neill EF, Ryan ND, Clements KM, Solares GR, Nelson ME, et al. Exercise training and nutritional supplementation for physical frailty in very elderly people. N Engl J Med. 1994;330:1769-75.

23. Reid KF, Callahan DM, Carabello RJ, Phillips EM, Frontera WR, Fielding RA. Lower extremity power training in elderly subjects with mobility limitations: a randomized controlled trial. Aging Clin Exp Res. 2008;20:337-43.

24. Brooks SV, Faulkner JA. Skeletal muscle weakness in old age: underlying mechanisms. Med Sci Sports Exerc. 1994;26:432-9.

25. Borkan GA, Hults DE, Gerzof SG, Robbins AH, Silbert CK. Age changes in body composition revealed by computed tomography. $\mathrm{J}$ Gerontol. 1983;38:673-7.

26. Aagaard P, Suetta C, Caserotti P, Magnusson SP, Kjaer M. Role of the nervous system in sarcopenia and muscle atrophy with aging: strength training as a countermeasure. Scand J Med Sci Sports. 2010;20:49-64.

27. Lexell J. Evidence for nervous system degeneration with advancing age. J Nutr. 1997;127:1011S-3S.

28. Kamen G, Sison SV, Du CC, Patten C. Motor unit discharge behavior in older adults during maximal-effort contractions. J Appl Physiol. 1995;79:1908-13.

29. Clark DJ, Patten C, Reid KF, Carabello RJ, Phillips EM, Fielding RA. Impaired voluntary neuromuscular activation limits muscle power in mobility-limited older adults. J Gerontol A Biol Sci Med Sci. 2010;65:495-502.

30. Clark DJ, Patten C, Reid KF, Carabello RJ, Phillips EM, Fielding RA. Muscle performance and physical function are associated with voluntary rate of neuromuscular activation in older adults. J Gerontol A Biol Sci Med Sci. 2011;66:115-21.

31. Hakkinen K, Newton RU, Gordon SE, McCormick M, Volek JS, Nindl BC, et al. Changes in muscle morphology, electromyographic activity, and force production characteristics during progressive strength training in young and older men. J Gerontol A Biol Sci Med Sci. 1998;53:B415-23.

32. Larsson L, Grimby G, Karlsson J. Muscle strength and speed of movement in relation to age and muscle morphology. J Appl Physiol. 1979;46:451-6.

33. Martin JC, Farrar RP, Wagner BM, Spirduso WW. Maximal power across the lifespan. J Gerontol A Biol Sci Med Sci. 2000;55: M311-6.

34. Frontera WR, Suh D, Krivickas LS, Hughes VA, Goldstein R, Roubenoff R. Skeletal muscle fiber quality in older men and women. Am J Physiol Cell Physiol. 2000;279:C611-8.

35. Pahor M, Manini T, Cesari M. Sarcopenia: clinical evaluation, biological markers and other evaluation tools. J Nutr Health Aging. 2009;13:724-8.

36. Newman AB, Kupelian V, Visser M, Simonsick E, Goodpaster B, Nevitt M, et al. Sarcopenia: alternative definitions and associations with lower extremity function. J Am Geriatr Soc. 2003;51:1602-9.

37. Lauretani F, Russo CR, Bandinelli S, Bartali B, Cavazzini C, Di Iorio A, et al. Age-associated changes in skeletal muscles and their effect on mobility: an operational diagnosis of sarcopenia. J Appl Physiol. 2003;95:1851-60.

38. Delmonico MJ, Harris TB, Visser M, Park SW, Conroy MB, Velasquez-Mieyer P, et al. Longitudinal study of muscle strength, quality, and adipose tissue infiltration. Am J Clin Nutr. 2009;90:1579-85.

39. Hairi NN, Cumming RG, Naganathan V, Handelsman DJ, Le Couteur DG, Creasey H, et al. Loss of muscle strength, mass (sarcopenia), and quality (specific force) and its relationship with functional limitation and physical disability: the Concord Health and Ageing in Men Project. J Am Geriatr Soc. 2010;58:2055-62.

40. Newman AB, Haggerty CL, Goodpaster B, Harris T, Kritchevsky $\mathrm{S}$, Nevitt $\mathrm{M}$, et al. Strength and muscle quality in a wellfunctioning cohort of older adults: the Health, Aging and Body Composition Study. J Am Geriatr Soc. 2003;51:323-30.

41. Rutkove SB. Electrical impedance myography: background, current state, and future directions. Muscle Nerve. 2009;40:936-46.

42. Rutkove S. Electrical impedance myography as a biomarker for ALS. Lancet Neurol. 2009;8:226. author reply 227.

43. Wang LL, Spieker AJ, Li J, Rutkove SB. Electrical impedance myography for monitoring motor neuron loss in the SOD1 G93A amyotrophic lateral sclerosis rat. Clin Neurophysiol. 2011

44. Aaron R, Esper GJ, Shiffman CA, Bradonjic K, Lee KS, Rutkove $\mathrm{SB}$. Effects of age on muscle as measured by electrical impedance myography. Physiol Meas. 2006;27:953-9.

45. Reeves ND, Maganaris CN, Narici MV. Ultrasonographic assessment of human skeletal muscle size. Eur J Appl Physiol. 2004;91:116-8.

46. Busch R, Kim YK, Neese RA, Schade-Serin V, Collins M, Awada $\mathrm{M}$, et al. Measurement of protein turnover rates by heavy water labeling of nonessential amino acids. Biochim Biophys Acta. 2006;1760:730-44.

47. Price JC, Holmes WE, Li KW, Floreani NA, Neese RA, Turner $\mathrm{SM}$, et al. Measurement of human plasma proteome dynamics with (2) $\mathrm{H}(2) \mathrm{O}$ and liquid chromatography tandem mass spectrometry. Anal Biochem. 2012;420:73-83.

48. Wintrobe MM. Blood of normal men and women: erythrocyte counts, hemoglobin and volume of packed red cells of two hundred and twenty-nine individuals. Bull Johns Hopkins Hosp. 1933;53:118-30.

49. Kanis JA, McCloskey EV, Johansson H, Strom O, Borgstrom F, Oden A. How to decide who to treat. Best Pract Res Clin Rheumatol. 2009;23:711-26.

50. Kanis JA, Johnell O, Oden A, Johansson H, McCloskey E. FRAX and the assessment of fracture probability in men and women from the UK. Osteoporos Int. 2008;19:385-97.

51. Hippisley-Cox J, Coupland C. Predicting risk of osteoporotic fracture in men and women in England and Wales: prospective derivation and validation of QFractureScores. BMJ. 2009;339: b4229.

52. Cesari M, Penninx BW, Pahor M, Lauretani F, Corsi AM, Rhys Williams $\mathrm{G}$, et al. Inflammatory markers and physical performance in older persons: the InCHIANTI study. J Gerontol A Biol Sci Med Sci. 2004;59:242-8

53. Schaap LA, Pluijm SM, Deeg DJ, Visser M. Inflammatory markers and loss of muscle mass (sarcopenia) and strength. Am J Med. 2006;119:526.e9-17.

54. Visser M, Pahor M, Taaffe DR, Goodpaster BH, Simonsick EM, Newman AB, et al. Relationship of interleukin- 6 and tumor necrosis factor-alpha with muscle mass and muscle strength in elderly 
men and women: the Health ABC Study. J Gerontol A Biol Sci Med Sci. 2002;57:M326-32.

55. Cesari M, Penninx BW, Lauretani F, Russo CR, Carter C, Bandinelli S, et al. Hemoglobin levels and skeletal muscle: results from the InCHIANTI study. J Gerontol A Biol Sci Med Sci. 2004;59: 249-54.

56. Penninx BW, Pahor M, Cesari M, Corsi AM, Woodman RC, Bandinelli S, et al. Anemia is associated with disability and decreased physical performance and muscle strength in the elderly. J Am Geriatr Soc. 2004;52:719-24.

57. Baumgartner RN, Koehler KM, Romero L, Garry PJ. Serum albumin is associated with skeletal muscle in elderly men and women. Am J Clin Nutr. 1996;64:552-8.

58. Visser M, Kritchevsky SB, Newman AB, Goodpaster BH, Tylavsky FA, Nevitt MC, et al. Lower serum albumin concentration and change in muscle mass: the Health, Aging and Body Composition Study. Am J Clin Nutr. 2005;82:531-7.

59. Proctor DN, O'Brien PC, Atkinson EJ, Nair KS. Comparison of techniques to estimate total body skeletal muscle mass in people of different age groups. Am J Physiol. 1999;277:E489-95.

60. Valenti G, Denti L, Maggio M, Ceda G, Volpato S, Bandinelli S, et al. Effect of DHEAS on skeletal muscle over the life span: the InCHIANTI study. J Gerontol A Biol Sci Med Sci. 2004;59: 466-72.

61. Morley JE, Baumgartner RN, Roubenoff R, Mayer J, Nair KS. Sarcopenia. J Lab Clin Med. 2001;137:231-43.

62. Perrini S, Laviola L, Carreira MC, Cignarelli A, Natalicchio A, Giorgino F. The GH/IGF1 axis and signaling pathways in the muscle and bone: mechanisms underlying age-related skeletal muscle wasting and osteoporosis. J Endocrinol. 2010;205:201-10.

63. Ceglia L. Vitamin D and skeletal muscle tissue and function. Mol Aspects Med. 2008;29:407-14.

64. Mastaglia SR, Seijo M, Muzio D, Somoza J, Nunez M, Oliveri B. Effect of vitamin D nutritional status on muscle function and strength in healthy women aged over sixty-five years. J Nutr Health Aging. 2011;15:349-54.

65. Cesari M, Incalzi RA, Zamboni V, Pahor M. Vitamin D hormone: a multitude of actions potentially influencing the physical function decline in older persons. Geriatr Gerontol Int. 2011;11:133-42.

66. Dalal M, Ferrucci L, Sun K, Beck J, Fried LP, Semba RD. Elevated serum advanced glycation end products and poor grip strength in older community-dwelling women. J Gerontol A Biol Sci Med Sci. 2009;64:132-7.

67. Howard C, Ferrucci L, Sun K, Fried LP, Walston J, Varadhan R, et al. Oxidative protein damage is associated with poor grip strength among older women living in the community. J Appl Physiol. 2007;103:17-20.

68. Semba RD, Ferrucci L, Sun K, Walston J, Varadhan R, Guralnik $\mathrm{JM}$, et al. Oxidative stress and severe walking disability among older women. Am J Med. 2007;120:1084-9.

69. Cesari M, Kritchevsky SB, Nicklas BJ, Penninx BW, Holvoet P, Koh-Banerjee $\mathrm{P}$, et al. Lipoprotein peroxidation and mobility limitation: results from the Health, Aging, and Body Composition Study. Arch Intern Med. 2005;165:2148-54.

70. Semba RD, Blaum C, Guralnik JM, Moncrief DT, Ricks MO, Fried LP. Carotenoid and vitamin E status are associated with indicators of sarcopenia among older women living in the community. Aging Clin Exp Res. 2003;15:482-7.

71. Semba RD, Lauretani F, Ferrucci L. Carotenoids as protection against sarcopenia in older adults. Arch Biochem Biophys. 2007;458:141-5

72. Bhasin S, He EJ, Kawakubo M, Schroeder ET, Yarasheski K, Opiteck GJ, et al. N-terminal propeptide of type III procollagen as a biomarker of anabolic response to recombinant human GH and testosterone. J Clin Endocrinol Metab. 2009;94:4224-33.

73. Chen F, Lam R, Shaywitz D, Hendrickson RC, Opiteck GJ, Wishengrad D, et al. Evaluation of early biomarkers of muscle anabolic response to testosterone. J Cachex Sarcopenia Muscle. 2011;2:45-56.

74. Bolliger MF, Zurlinden A, Luscher D, Butikofer L, Shakhova O, Francolini $\mathrm{M}$, et al. Specific proteolytic cleavage of agrin regulates maturation of the neuromuscular junction. J Cell Sci. 2010;123:3944-55.

75. Butikofer L, Zurlinden A, Bolliger MF, Kunz B, Sonderegger P. Destabilization of the neuromuscular junction by proteolytic cleavage of agrin results in precocious sarcopenia. FASEB J. 2011;25:4378-93.

76. Rolland Y, Lauwers-Cances V, Cristini C, Abellan van Kan G, Janssen I, Morley JE, et al. Difficulties with physical function associated with obesity, sarcopenia, and sarcopenic-obesity in community-dwelling elderly women: the EPIDOS (EPIDemiologie de l'OSteoporose) Study. Am J Clin Nutr. 2009;89:1895-900.

77. Zamboni M, Mazzali G, Fantin F, Rossi A, Di Francesco V. Sarcopenic obesity: a new category of obesity in the elderly. Nutr Metab Cardiovasc Dis. 2008;18:388-95.

78. von Haehling S, Morley JE, Coats AJS, Anker SD. Ethical guidelines for authorship and publishing in the Journal of Cachexia, Sarcopenia and Muscle. J Cachexia Sarcopenia Muscle. 2010;1:7-8. 